monitor the organisation and severity of the salivary gland infiltrate has been hampered by the lack of sensitive tools to describe TLS extent and features.

Objectives: To investigate CXCL13 and CXCL12 serum and tissue expression and to find any possible association with clinical, histological and laboratory features.

Methods: We studied histological features of the minor salivary glands (MSG) and sera of respectively fifty and seventy (table 1) unselected consecutive patients with pSS (AECG criteria). Concentration of CXCL13 and CXCL12 were evaluated by ELISA in patient sera and eleven healthy controls $(\mathrm{HC})$. Paraffin embedded MSG were studied by haematoxylin/eosin and anti-CD3, anti-CD20, anti-CD21 staining. Images analysis was used to calculate focus score (FS), mean foci area, percentage of infiltration (\%i), segregated foci (\%SF),\%GCs and lymphoepitelial lesions (\%LEL). GCs from MSG and tonsils were microdissected and quantitative PCR was used to test CXCL12 and CXCL13 transcripts.

Results: Histological analysis unveiled strong correlations between the mean foci area with the\%i and the presence of SF; positive correlations were also observed between the $\%$ i and both the FS and\%SF. This was significantly higher in patients exhibiting SF. The $\%$ of SF positively correlated with FS, presence of\% GC and\%LEL that also correlated with the $\%$ i and the $\%$ SF (image). Mean CXCL13 and CXCL12 serum levels were significantly higher in pSS compared to $\mathrm{HC}[(124.12 \pm 119.73 \mathrm{pg} / \mathrm{ml}$ vs $8.9 \pm 15.4 \mathrm{pg} / \mathrm{ml}(\mathrm{p}=0.001)$ and $34.6 \pm 54.2 \mathrm{pg} / \mathrm{ml}$ vs $2.5 \pm 8.3 \mathrm{pg} / \mathrm{ml}(\mathrm{p}=0.05)$, respectively]. CXCL13 was significantly higher in patients with SF, with GCs and LEL and correlated with the mean foci area, the\%i, the FS and the percentage of LEL. Higher CXCL13 levels were associated with the presence of antibodies and other biological findings including hyperglobulinemia. Higher CXCL13 levels were also able to discriminate patients with lymphoma $(p=0.009)$. CXCL12 levels correlated with the FS, \%i and\% of LEL. Transcript analysis showed no difference in the expression of CXCL13 between MSG and tonsil GC, whilst CXCL12 was found significantly higher in MSG $(p<0.0001)$.
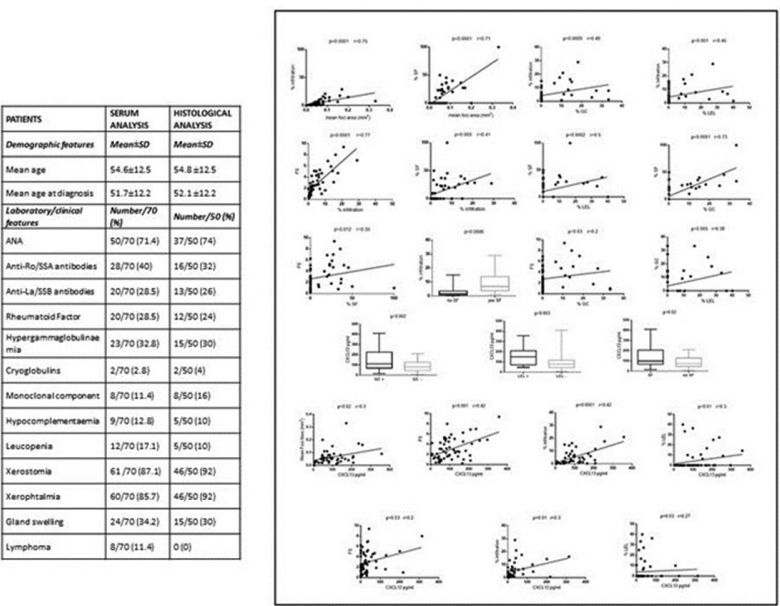

Conclusions: Our results suggest the utility to expand the parameters of histologic evaluation of MSG, whilst reinforcing the role of the FS as reliable instrument to reflect the severity of inflammation. Analysis of MSG infiltration and foci segregation was able to identify subjects with increased proliferative risk. We demonstrated that serum CXCL13, is a biomarker of histological severity and is able to stratify patients with lymphoma. The high levels of CXCL12 in MSG GC suggest a differential biology of TLS in the SG, probably implicated in aberrant B cell clone survival.

Disclosure of Interest: None declared

DOI: 10.1136/annrheumdis-2018-eular.5192

\section{FRI0290 PRO-INFLAMMATORY CYTOKINES PROMOTE GLOBAL AND GENE-SPECIFIC CHANGES IN DNA METHYLATION IN SALIVARY GLANDS FROM SJÖGREN'S SYNDROME PATIENTS}

C. Lagos ${ }^{1}$, S. Aguilera ${ }^{2}$, P. Carvajal ${ }^{1}$, D. Jara ${ }^{1}$, I. Castro ${ }^{1}$, S. González ${ }^{3}$, U. Urzua ${ }^{1}$, M.J. Barrera ${ }^{1}$, C. Molina ${ }^{3}$, C. Leyton ${ }^{1}$, M.-J. González ${ }^{1}$. ${ }^{1}$ ICBM, Facultad de Medicina, Universidad de Chile; ${ }^{2}$ Reumatología, Clínica INDISA; ${ }^{3}$ Patología Oral, Universidad Mayor, Santiago, Chile

Background: Salivary glands (SG) from Sjögren's syndrome (SS)-patients show chronic inflammation and altered unfolded protein response (UPR). Pro-inflammatory cytokines induce epigenetic changes including DNA methylation, a dynamic and complex process where cytosines of $\mathrm{CpG}$ sites are methylated $(5 \mathrm{mC})$ by DNA methyltransferases (DNMT), and then hydroxymethylated $(5 \mathrm{hmC})$ by TET enzymes.
Objectives: To determine DNA methylation in promoters of specific UPR genes and levels of $5 \mathrm{mC}, 5 \mathrm{hmC}$, DNMT and TET enzymes in labial-SG from SS-patients and cytokine effects on global DNA methylation and DNA methylation of specific gene promoters in human SG cells

Methods: SG biopsies from 23 SS-patients and 15 controls were analysed. $5 \mathrm{mC}$ and $5 \mathrm{hmC}$ levels were assessed by immunofluorescence (IF), quantified independently in epithelial and inflammatory cells and correlated with focus score mRNA levels of DNA methyltransferases (DNMT1, DNMT3a, and DNMT3b), and dioxygenases TET1, TET2 and TET3 were determined by RT-qPCR. The in situ protein levels of these enzymes were evaluated by IF. Specific DNA methylation of IRE1 $\alpha$, XBP-1, GRP78, ATF4 and ATF6 $\alpha$ gene promoters was evaluated by MS-HRM. Human SG cells (HSG) and 3D-acini were incubated with 1 or $10 \mathrm{ng}$ $\mathrm{mL}$ TNF- $\alpha$ and IFN- $\gamma$ for 24 hour. Levels of $5 \mathrm{mC}, 5 \mathrm{hmC}$, methylation of specific gene promoters and transcript levels of UPR molecules, DNMTs and TETs were determined.

Results: LSG epithelial cells from SS-patients showed significant increase of DNA hydroxymethylation and decrease of DNA methylation. Their $5 \mathrm{hmC}$ levels were positively and $5 \mathrm{mC}$ levels inversely correlated with focus score. Inflammatory cells showed high levels of $5 \mathrm{mC}$ and DNMTs and low levels of $5 \mathrm{hmC}$ Increased mRNA levels of DNMT1, DNMT3a, and TET2 and a significant decrease of TET1 and TET3 were observed. Protein levels of TET2 were significantly higher in LSG epithelial cells from SS-patients. The above results were reproduced in HSG cells where cytokine stimulation increased TET2 and 5hmC and decreased $5 \mathrm{mC}$ levels. SS-patients SG and 3D-acini stimulated with cytokines, revealed an inverse correlation between gene promoter DNA methylation and transcript levels of IRE1 $\alpha$, XBP-1, GRP78, ATF4 and ATF6 $\alpha$

Conclusions: Pro-inflammatory cytokines promoted increase of $5 \mathrm{hmC}$ and decrease of $5 \mathrm{mC}$ in SG epithelial cells likely by inducing TET2 expression. Global DNA hypomethylation have also been observed in other autoimmune diseases, where some specific genes appear to be hypermethylated. Our results showed a concordance between the methylation of UPR gene promoters and its transcriptional regulation, which was modulated by cytokines. High DNMTs protein levels observed in inflammatory cells are consistent with high levels of $5 \mathrm{mC}$ suggesting that increased DNMTs transcript levels in LSG from SS-patients come from inflammatory cells. $5 \mathrm{mC}$ has been associated with transcriptional repression, while $5 \mathrm{hmC}$ with transcriptional activation, therefore, we postulate that changes of DNA hydroxymethylation resulting from altered levels of TET2 could have an etiopathogenic role in Sjögren's syndrome.

Acknowledgements: Fondecyt-1160015, Fondecyt-Iniciación-11170049, IC Fondecyt-Postdoctorado-3170023, MJB

Disclosure of Interest: None declared

DOI: 10.1136/annrheumdis-2018-eular.3784

\section{FRI0291 \\ CHARACTERISATION OF MONOCYTE POPULATIONS IN PERIPHERAL BLOOD OF SLE PATIENTS}

S.M. Anderson, D. Shah, D. Webb, P. Adusumalli, S. Visvanathan, J. Fine,

G. Nabozny, M. Ramanujam. Boehringer Ingelheim, Ridgefield, USA

Background: Systemic lupus erythematosus (SLE) is an autoimmune diseases characterised by dysregulation of immune cell function with numerous clinical manifestations. Along with $B$ and T cells, myeloid cells play an important role in disease pathogenesis. Circulating monocytes are recruited to sites of inflammation where they play an active role in mediating tissue inflammation and injury.

Objectives: To understand the changes in circulating monocyte phenotypes in SLE patients.

Methods: Peripheral blood was collected from 25 female SLE patients who were autoantibody positive (dsDNA/Ro/La/SM), with SLEDAls between 2 and 6 (all patients on hydroxychloroquine, 6 patients on steroids, and 3 on MMF); TR BIO Inc, Hawthorne, NY). Gender matched healthy controls $(27 \mathrm{HC})$ were obtained from $\mathrm{BI}$ volunteers. Using multicolor flow cytometry, the percent changes in the expression of HLA-DR/DP/DQ, CD163, CD40, CCR1, CX3CR1 and CD11b on $\mathrm{CD}_{14}{ }^{+}, \mathrm{CD} 14^{+} \mathrm{CD} 16^{+}$, and $\mathrm{CD} 16^{+}$monocytes were evaluated. In a smaller subset of these patients ( 8 SLE and $15 \mathrm{HC}$ ), circulating endothelial cell (CECs) phenotyping was performed by evaluating: CD45, CD133/1, CD106, CD105, CD31, CD46, CD34, and CX3CL1. Human 38-plex cytokine/chemokine multiplexes (Luminex, Millipore) were used to evaluate serum analytes. To understand the regulation of cytokines and chemokines from the monocyte population, $\mathrm{HC}$ monocytes were sorted to $95 \%$ purity, stimulated with disease-relevant TLR ligands, and profiled for their analytes. Statistical analyses were performed using GraphPad Prism, version 7, GraphPad Software Inc. and determined by the Mann-Whitney t-test. Results: SLE patients had a significant increase in MFI for CD $14^{+} \mathrm{CD} 11 \mathrm{~b}^{+}$and $\mathrm{CD}_{16}{ }^{+} \mathrm{CD} 11 \mathrm{~b}^{+}$and percentages as well as MFI for $\mathrm{CD} 14^{+} \mathrm{CD} 163^{+}$, $\mathrm{CD}_{16}{ }^{+} \mathrm{CD}_{163^{+}}$, and $\mathrm{CD} 14^{+} \mathrm{CD} 16^{+} \mathrm{CD} 163^{+}$as compared to controls,. An increase in the percentage of $\mathrm{CX} 3 \mathrm{CR} 1^{+} \mathrm{CD} 14^{+}$and $\mathrm{CD} 14^{+} \mathrm{CD} 16^{+}$monocytes were observed, see table 1. Concurrently, an increase in CX3CL1 percentage was observed in immature circulating endothelial cells (iCECs) $(p<0.0366)$ as compared to $\mathrm{HC}$. Increases in monocyte/macrophage-associated cytokines and 
chemokine in the serum $(\mathrm{pg} / \mathrm{mL})$ of SLE patients compared to HC, respectively, included: sCX3CL1 (478.6 $\pm 46.19 ; 235.4 \pm 140.8)$ and MCP-1 $(2657 \pm 466.2 ; 648.5$ $\pm 69.6)(p<0.00001)$, MIP1B $(141.0 \pm 10.71 ; 79.31 \pm 10.69)(p<0.0003)$, and TNF $\alpha$ $(59.07 \pm 6.64 ; 29.31 \pm 3.15)(p<0.0041$. Additionally, the disease severity and endothelial dysfunction associated biomarker VEGF increased in SLE patients (445.6.3 $\pm 48.1 \mathrm{pg} / \mathrm{mL})$ compared to $\mathrm{HC}(231.8 \pm 47.03 \mathrm{pg} / \mathrm{mL})(\mathrm{p}<0.0069)$. Lastly, $\mathrm{HC}$ monocyte subsets were stimulated with TLR7 and 8 ligands and supernatants evaluated for the analytes described above, see table 2 .

Abstract FRI0291 - Table 1

\begin{tabular}{|c|c|c|c|c|c|c|c|}
\hline \multirow{2}{*}{\begin{tabular}{|c|}
$\begin{array}{c}\text { Monocyte } \\
\text { Subset }\end{array}$ \\
\end{tabular}} & \multirow{2}{*}{ Marker } & \multicolumn{2}{|c|}{ Healthy Control (Mean \pm SEM) } & \multicolumn{2}{|c|}{ SLE Patients (Mean \pm SEM) } & \multicolumn{2}{|c|}{ P-Value } \\
\hline & & Percentage & MFI & \begin{tabular}{|l} 
Percengate \\
\end{tabular} & MFI & Percentage & MFI \\
\hline $\mathrm{CD} 14^{+}$ & CCR1 & $71.18 \pm 5.31$ & $820.7 \pm 55.8$ & $71.81 \pm 6.425$ & $880.9 \pm 110.4$ & 0.799 & 0.775 \\
\hline $\mathrm{CD}_{16}{ }^{\circ}$ & CCR1 & $19.41 \pm 5.14$ & $1768.2 \pm 548.7$ & $33.90 \pm 7.86$ & $1716.6 \pm 473.9$ & 0.108 & 0.329 \\
\hline $\mathrm{CD} 14^{4} / \mathrm{CD} 16^{*}$ & CCR1 & $34.87 \pm 6.01$ & $1933.2 \pm 441.4$ & $49.50 \pm 7.13$ & $1935.1 \pm 396.4$ & 0.124 & 0.420 \\
\hline $\mathrm{CD} 14^{+}$ & $\mathrm{CD} 11 \mathrm{~b}$ & $97.58 \pm 0.59$ & $5289.5 \pm 410.9$ & $98.44 \pm 0.29$ & $6868.2 \pm 626.6$ & 0.985 & 0.007 \\
\hline${\mathrm{CD} 16^{\circ}}^{\circ}$ & $\mathrm{CD} 11 \mathrm{~b}$ & $55.22 \pm 4.48$ & $1289.6 \pm 146.6$ & $53.13 \pm 4.34$ & $2075.15 \pm 324.4$ & 0.819 & 0.021 \\
\hline $\mathrm{CD} 14^{\circ} / \mathrm{CD} 16^{\circ}$ & $\mathrm{CD} 11 \mathrm{~b}$ & $93.82 \pm 1.60$ & $4580.8 \pm 327.5$ & $93.72 \pm 2.32$ & $5640.9 \pm 579.0$ & 0.861 & 0.102 \\
\hline $\mathrm{CDN14}^{+}$ & $\mathrm{CD} 40$ & $7.61 \pm 2.72$ & $612.2 \pm 200.7$ & $8.06 \pm 3.08$ & $806.7 \pm 266.4$ & 0.861 & 0.333 \\
\hline $\mathrm{CD} 16^{*}$ & CD40 & $7.37 \pm 3.05$ & $1640.6 \pm 575.6$ & $15.65 \pm 6.09$ & $1466.1 \pm 473.6$ & 0.200 & 0.511 \\
\hline $\mathrm{CD} 14^{+} / \mathrm{CD} 16^{+}$ & $\mathrm{CD} 40$ & $9.77 \pm 2.92$ & $1116.7 \pm 225.2$ & $12.33 \pm 4.17$ & $1389.1 \pm 348.7$ & 0.643 & 0.389 \\
\hline $\mathrm{CD} 14^{+}$ & $\mathrm{CD} 163$ & $65.77 \pm 5.42$ & $1499.4 \pm 110.4$ & $85.24 \pm 3.08$ & $2198.3 \pm 171.0$ & 0.006 & 0.001 \\
\hline CD16 ${ }^{\circ}$ & $\mathrm{CD} 163$ & $15.21 \pm 3.06$ & $563.88 \pm 94.74$ & $24.08 \pm 3.34$ & $757.6 \pm 106.6$ & 0.022 & 0.022 \\
\hline $\mathrm{CD} 14^{\top} / \mathrm{CD} 16^{\circ}$ & $\mathrm{CD} 163$ & $61.00 \pm 4.96$ & $1358.0 \pm 108.6$ & $76.72 \pm 5.36$ & $2028.3 \pm 198.0$ & 0.014 & 0.014 \\
\hline $\mathrm{CD}_{14}{ }^{+}$ & CX3CR1 & $42.82 \pm 2.93$ & $796.2 \pm 70.58$ & $63.0 \pm 5.91$ & $1062 \pm 100.1$ & 0.005 & 0.047 \\
\hline CD16 ${ }^{\circ}$ & CX3CR1 & $86.47 \pm 2.53$ & $2471.8 \pm 223.5$ & $85.50 \pm 4.08$ & $2947.3 \pm 336.3$ & 0.742 & 0.378 \\
\hline & & & & & & & \\
\hline
\end{tabular}

Abstract FRI0291 - Table 2

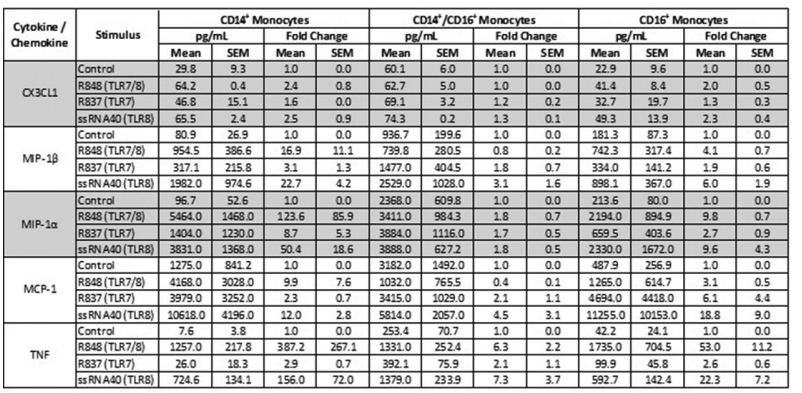

Conclusions: Cell surface markers of activation and adhesion increased in SLE monocyte subsets compared to $\mathrm{HC}$. In parallel, increased inflammatory cytokines and chemokines that attract monocytes to tissues were increased in the serum of these patients. Linking a possible source of this increase in serum analytes, HC monocyte subsets were stimulated with disease-relevant ligands and evaluated in culture. Along with increased monocyte expression of CX3CR1, preliminary data demonstrates an increase in CX3CL1 expression on endothelial progenitor cells (EPCs) and immature and mature circulating endothelial cells (iCECs and mCEC respectively) in active disease.

Disclosure of Interest: None declared

DOI: 10.1136/annrheumdis-2018-eular.3002

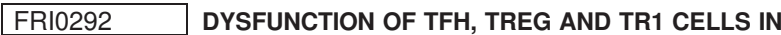 APOE-/- FASLGLD C57BL/6 MICE WITH LUPUS SYMPTOMS AND ATHEROSCLEROSIS}

S. Wang, G. Yao, L. Sun. Department of Rheumatology and Immunology, The Affiliated Drum Tower Hospital of Nanjing University Medical School, Nanjing, China

Background: Cardiovascular disease due to atherosclerosis is currently recognised as one of the leading causes of death among patients with systemic lupus erythematosus (SLE). It is well established that dysfunction of lymphocytes contribute to the pathogenesis of SLE. Recent studies also showed infiltration of several subsets of lymphocytes in atherosclerotic lesions and their various contributions to atherosclerosis were uncovered in experimental models and patients. However, the predominant and specific subsets of lymphocytes that play critical role in the pathogenesis of SLE patients with cardiovascular complications remained to be elucidated.

Objectives: This study aims to define the dominant population of lymphocytes in mice with combination of lupus and atherosclerosis.

Methods: The mouse model of accelerated atherosclerosis in lupus ( $\mathrm{ApoE}^{-/}$ Fas ${ }^{\text {gld }}$ B6 mice) was generated from apolipoprotein E-deficient $\left(\mathrm{apoE}^{-/-}\right)$and Fas $\left.\right|^{\text {gld }} \mathrm{C} 57 \mathrm{BL} / 6$ mice. The lupus-like autoimmunity and atherosclerotic lesions was evaluated. The lymphocytes of spleen and peripheral blood were analysed by flow cytometry.
Results: The results of PCR and sequencing showed that the double-mutant ApoE ${ }^{-/}$Fas $\left.\right|^{\text {gld }}$ B6 mice were generated. Spleens from 5 month-old $A p o E^{-/}$Fas ${ }^{\text {gld }}$ B6 mice were significantly enlarged compared with wild type mice (WT mice) $\mathrm{ApoE}^{-/-} \mathrm{Fas}^{\text {gld }} \mathrm{B} 6$ mice displayed a pattern of glomerulonephritis typically found in SLE and showed marked C3, IgG and IgM deposits in the glomeruli. Anti-dsDNA antibody and high levels of creatinine were detected in the serum of $\mathrm{ApoE}^{-/-} \mathrm{Fas}^{\text {gld }}$ B6 mice. These results indicated that the $\mathrm{ApoE}^{-/-} \mathrm{Fas}^{\text {gld }} \mathrm{B} 6$ mice have typical characteristics of SLE. Oil red O staining revealed that there was significantly increased atherosclerotic lesion area at the proximal aorta in $\mathrm{ApoE}^{-/-} \mathrm{Fas}^{\text {gld }} \mathrm{B} 6$ mice compared with WT mice (figure $1 \mathrm{a}, \mathrm{b}$ ). The frozen section of myocardium stained by oil red $\mathrm{O}$ revealed that lipid deposited in myocardial cells of $\mathrm{ApoE}^{-1}$ Fas ${ }^{\text {lld }}$ B6 mice (figure $1 \mathrm{c}, \mathrm{d}$ ). As excepted, total cholesterol, LDL cholesterol and triglyceride were significantly increased, while HDL cholesterol decreased in the double-mutant mice. These results indicated that $\mathrm{ApoE}^{-/} \mathrm{Fas}^{\text {gld }} \mathrm{B} 6$ mice had accelerated atherosclerosis. a

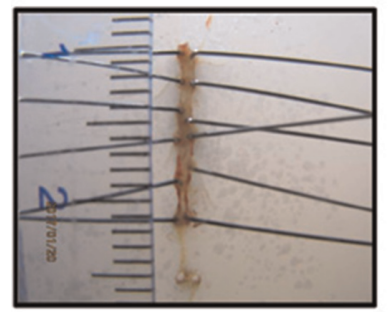

C

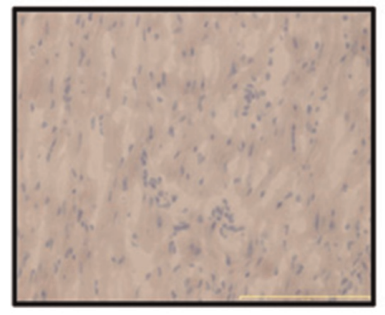

B6 b

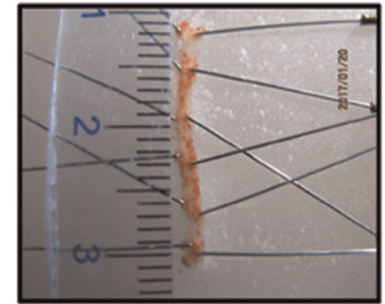

d

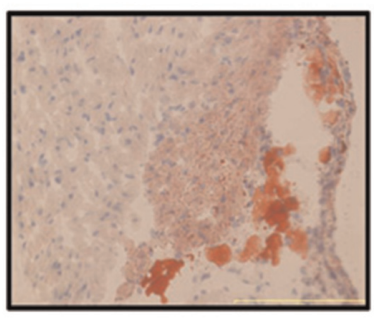

ApoE-/-gld
Conclusions: The ApoE ${ }^{-/-}$Fas $\left.\right|^{\text {gld }} \mathrm{B} 6$ mice simultaneous exhibit SLE and atherosclerosis characteristics. Our findings suggested that proinflammatory M1 macrophages and Tfh cells were increased, while the anti-inflammatory Treg and Tr1 cells were decreased and the imbalance of these cells and their releasing cytokines contributed to progression in atherosclerosis with SLE. Further studies may validate these cells as potential targets for treating SLE patients with atherosclerosis.

Disclosure of Interest: None declared

DOI: 10.1136/annrheumdis-2018-eular.2864

\section{FRI0293 IMBALANCE IN CIRCULATING SUBSETS OF INNATE LYMPHOID CELLS IS LINKED TO DISEASE ACTIVITY AND TYPE I INTERFERON SIGNATURE IN PRIMARY SJÖGREN'S SYNDROME}

S.L. Blokland ${ }^{1,2}$, L.L. van den Hoogen ${ }^{1,2}$, E.F. Leijten ${ }^{1,2}$, A.A. Kruize ${ }^{1}$, T. R. Radstake ${ }^{1,2}$, J.A. van Roon ${ }^{1,2}$. ${ }^{1}$ Rheumatology and Clinical Immunology; ${ }^{2}$ Laboratory of Translational Immunology, Umc Utrecht, Utrecht, Netherlands

Background: Recent studies indicate an important role for innate lymphoid cells (ILCs) in the pathophysiology of rheumatic diseases. In rheumatoid arthritis and spondyloarthropathies elevated numbers of subsets of ILCs have been found at the site of inflammation producing cytokines including IFN- $\gamma$ and IL-22 and in addition, group 3 ILC have been suggested to be involved in formation of ectopic lym phoid structures in rheumatic diseases, Shikhagaie Nat Rev Rheumatol 2017 Wenink A and R 2017). ILC3-like cells producing IL-22 have been found in the salivary glands of pSS patients. Ciccia ARD 2012 However, circulating ILC have not yet been studied in primary Sjögren's syndrome (pSS) and systemic lupus erythematosus (SLE). Furthermore, SLE and pSS are characterised by presence of a type I interferon (IFN) signature in a large proportion of the patients. Animal studies in HIV and asthma implicate type I IFN, produced by plasmacytoid dendritic cells (pDCs), to regulate the survival of group 2 and group 3 ILCs (ILC2 and 